\title{
Catalytically Assisted Electrochemical Oxidation of Dye Acid Red B
}

\author{
Z. Shen, W. Wang, J. Jia, X. Feng, W. Hu, A. Peng
}

\begin{abstract}
This study focused on the degradation of dye Acid Red B in a catalytic electrolysis system with a semiconductor suspended in the electric field. The study showed that the addition of titanium dioxide substantially enhances the degradation of dye and that a semiconductor catalyst can improve electrolysis efficiency. This catalytic system has great potential to be applied commercially with the development of the catalyst. Analytical measurements show that some acidic compounds are produced in the treatment process and that biodegradability of the solution increases after electrolysis because of the breakdown of molecules. The UV-visible spectrum also indicates that the conjugated bonds of dye Acid Red B must be destroyed and that the molecules are broken into small ones. Furthermore, the results from the IR spectrum indicate that the nitrogen-nitrogen double bond of dye Acid Red B must be oxidized to nitrate. Electrochemical measurements show an apparent dye oxidation peak from 0.65 to $0.85 \mathrm{~V}$ (versus the saturated calomel electrode) in dye solution $(10 \mathrm{~g} / \mathrm{L})$, confirming that dye is oxidized in this catalytic system. Water Environ. Res., 74, 117 (2002).
\end{abstract}

KEYWORDS: catalyst, semiconductors, electrolysis, dye treatment.

\section{Introduction}

Effluents from the textile and dye synthesizing industry usually contain dyes. Although these effluents are a small component of the typical parameters used to measure pollutant concentrations, there is increasing concern about them because of their resistance to degradation in typical biological wastewater treatment systems, where almost no color removal is achieved. Additionally, their high $\mathrm{pH}$, temperature, and large amount of suspended solids are well known (DeFazio and Lemley, 1999, and Vlyssides and Israilides, 1998).

Many decoloration methods have been conducted on wastewaters containing dyes. Because the composition of the wastewater varies widely, most traditional decoloration methods are becoming inadequate. Although chlorination and ozonation have been proposed as potential alternatives, both the costs and secondary toxic byproducts arising from the residual chlorine need to be further ascertained to ensure the competence of these methods. Activated carbon adsorption is another efficient decoloration method. However, it is not desirable because of both high-operating costs as well as raw costs (Lin and Peng, 1996, and Vlyssides et al., 1999).

Because of its success at color removal, electrochemical technology has received increasing attention (DeFazio and Lemley, 1999; Lin and Peng, 1996; and Vlyssides and Israilides, 1998). Advances in electrode materials have led to progress in electrolytic effectiveness (Brillas et al., 1998, and Rodgers et al., 1999). In the past, graphite has frequently been used as an anode during electrochemical treatment because it is relatively economical and yields satisfactory results. Titanium electrodes covered with thin layers of electrodeposited noble metals have recently been used for electro-oxidation. Electrodes can also be coated with ruthenium, rhodium, lead, and stannum oxide (Vlyssides and Israilides, 1998). These high-oxygen overvoltage anodes have been used to destroy pollutants in wastewater (Casado and Brillas, 1996; Nicola and Badea, 1996; and Tezuka and Jwasaki, 1996). Naohide et al. (1998) treated dyestuff using a lead dioxide $\left(\mathrm{PbO}_{2}\right)$ anode. In their study, Orange II was decolorized completely by a 120-minute electrolysis using a $\mathrm{PbO}_{2}$ anode at a current density of $0.2 \mathrm{~A} / \mathrm{cm}^{2}$. Polcaro et al. (1999) also studied the performance of a titaniumlead dioxide $\left(\mathrm{Ti} \mid \mathrm{PbO}_{2}\right)$ anode during electrolysis of 2-cholorophenol in terms of the faradaic yield and the fraction of toxic intermediates removed. Both graphite and $\mathrm{Ti} \mid \mathrm{PbO}_{2}$ anodes were used in this study.

The existence of a catalyst in the electric field can also enhance treatment efficiency. Chen and Zhu (1998) used metal dioxide to treat three types of organic pollutants (phenol, phenylamine, and dimethyl phthalate) in wastewater. The existence of hydrogen peroxide and the hydroxide radical were verified during the electrolytic catalysis process. The results showed that removal efficiency depended on the yield of intermediate compounds in the system. Organic pollutants were effectively removed when the hydrogen peroxide yield increased. Notable removal efficiency was reached when hydrogen peroxide yield was more than $0.3 \mathrm{mg} / \mathrm{L}$. A semiconductor catalyst can be used in an electrochemical process as well as a photodegradation system (Moctezuma et al., 1999, and Taghizadeh et al., 2000). Removal of xenobiotic compounds, such as chlorophenols and pesticides, from municipal and industrial wastewater is an important task because of their toxicity and tendency to bioaccumulate. Among the several methods proposed, photodegradation catalyzed by suspended inorganic semiconductors (i.e., titanium dioxide $\left[\mathrm{TiO}_{2}\right]$ ) has received widespread attention lately because this process leads to nontoxic final products and shows a high degradation efficiency (Campanella et al., 1995). Titanium dioxide is a semiconductor catalyst that has been widely studied since the 1970 s. The $\mathrm{TiO}_{2}$ electrode has been used to degrade 4-chlorophenol and dyes (Kesselman et al., 1997, and Ronaldo et al., 1999).

The exact mechanisms of electrochemical oxidation, which occur during electrolysis, are complicated and not yet entirely clear. Based on the intermediate products and radicals that can be determined during electrolysis, such as ozone, hydrogen peroxide, $\mathrm{Cl}_{2}$, $\mathrm{O}_{2}, \mathrm{OH}^{*}, \mathrm{O}^{*}, \mathrm{ClOH}^{*}$, and other oxidants, it has been postulated that organic pollutants can be directly or indirectly oxidized (Vlyssides et al., 1999).

To study the effectiveness of a semiconductor catalyst in the electric field, titanium dioxide was used as a catalyst suspended in the electric field in this study. Titanium dioxide was speculated to enhance electrolysis efficiency. To further study the degradation mechanisms, electrochemical measurements, IR, and other analytical methods were also carried out. 


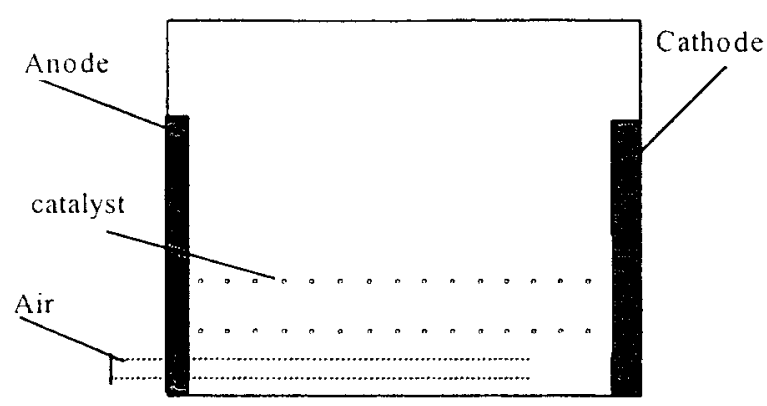

Figure 1-Structure of catalytic electrolysis equipment.

Acid dyes are the popular choice for dying nylon or polyamide fiber, wool, and silk. This study examined the treatment of Acid Red B (Acid Red 14, an azo dye), the structural formula of which is as follows:<smiles>CS(=O)(=O)c1ccc(N=Nc2cc(S(C)(=O)=O)c3ccccc3c2O)c2ccccc12</smiles>

\section{Materials and Methods}

Electrolysis Apparatus. Figure 1 gives a schematic of the electrolysis equipment used in this study. Graphite and $\mathrm{Ti} \mid \mathrm{PbO}_{2}$ were used as anodes, while activated-carbon felt was used as the cathode. To stir the solution, air was pumped into the bottom of the equipment. Both the graphite and $\mathrm{Ti} \mid \mathrm{PbO}_{2}$ anodes had the same area $\left(21 \mathrm{~cm}^{2}\right)$. Rutile titanium dioxide (powder) was used as an electric field catalyst suspended between the electrodes. Each liter of solution in this electrolysis system contained $5 \mathrm{~g}$ of titanium dioxide.

Analytical Measurements. Solution pHs were detected by a pH-mV meter (Cole-Parmer Instrument Co., Vernon Hills, Illinois). A total organic carbon (TOC) analyzer (TOC-500, Shimadzu, Japan) detected concentrations of organic carbon in solutions and color was analyzed by spectrophotometer (U-3010, Hitachi, Tokyo, Japan). Each dye solution was scanned and its maximum absorbency visible wavelength was detected. Both the color and TOC removal ratios $\left(\mathrm{R}_{\text {color }}\right.$ and $\mathrm{R}_{\mathrm{TOC}}$, respectively) were calculated as follows:

$$
\begin{gathered}
\mathrm{R}_{\text {color }}(\%)=\left(\mathrm{ABS}_{\mathrm{o}}^{514}-\mathrm{ABS}^{514}\right) / \mathrm{ABS}_{\mathrm{o}}^{514} \times 100 \% \\
\mathrm{R}_{\mathrm{TOC}}(\%)=\left(\mathrm{TOC}_{\mathrm{o}}-\mathrm{TOC}\right) / \mathrm{TOC}_{\mathrm{o}} \times 100 \%
\end{gathered}
$$

Where

$\mathrm{ABS}^{514}=$ average of absorbency values at maximum absorbency visible wavelength (514 $\mathrm{nm}$ for Acid Red B),

$\mathrm{ABS}_{\mathrm{o}}^{514}=\mathrm{ABS}^{514}$ value before electrolysis, and

$\mathrm{TOC}_{\mathrm{o}}=$ TOC value before electrolysis.

A graphite electrode in solutions both with dye Acid Red B (10 $\mathrm{g} / \mathrm{L}$ ) and without was analyzed electrochemically in a potentiostatgalvanostat (model 273A, EG\&G Princeton Applied Research, Princeton, New Jersey), with a standard determination cell consisting of platinum as a counter electrode (amalgam electrode). As usual, a silver-silver chloride $(\mathrm{Ag} \mid \mathrm{AgCl})$ electrode was used as a reference. The electrochemical behavior of the electrode surface was studied by voltametry (cyclic voltametry) at $20 \mathrm{mV} / \mathrm{s}$ from open circuit potential to $1.2 \mathrm{~V}$ versus $\mathrm{Ag} \mid \mathrm{AgCl}$, using $0.05 \mathrm{~mol} /$ $\mathrm{dm}^{3}$ sodium sulfate solution at normal temperature.

An IR spectrometer (Paragon 1000, Perkin-Elmer, Norwalk, Connecticut) was used to analyze the IR spectrum. Before IR detection, a typical solution after electrolysis at a color removal ratio of more than $95 \%$ was added into surplus barium chloride, depositing the sulfate ion. Next, the solution was condensed and air-dried to a constant weight.

Operation. Electrolysis was conducted at $8 \mathrm{~V}$ (direct current [dc]). The dye concentration was $60 \mathrm{mg} / \mathrm{L}$ and the solution contained $0.05 \mathrm{~mol} / \mathrm{L}$ sodium sulfate as an electrolyte. Solution conductivity was $8.65 \mathrm{~ms} / \mathrm{cm}$, which was detected by a conductivity meter (model DDS-11A, Hongyi Analytic Equipment Corporation, Shanghai, China). Volume electric current density was detected with time. Because electric current values differ under various electrolytic conditions, energy consumption was used instead of time to compare the results under various electrolytic conditions. Energy consumption was calculated as the product of current, voltage, and electrolysis time. During electrolysis, the TOC and color of the solution were determined with a TOC analyzer (Shimadzu) and spectrophotometer (Hitachi), respectively.

\section{Results and Discussion}

Color Removal. Figures 2 and 3 give the decoloration results of electrolysis using a graphite and $\mathrm{Ti} \mid \mathrm{PbO}_{2}$ anode, respectively. By comparison, color reduction was more efficient with the catalysis of titanium dioxide. When the electrolysis process consumes 1 $\mathrm{Wh} / \mathrm{L}$ of electric energy, color is removed more than $90 \%$ with a semiconductor as a catalyst using a graphite anode. However, it is removed less than $70 \%$ without the catalyst. Using a $\mathrm{Ti} \mid \mathrm{PbO}_{2}$ anode with a catalyst, electrolysis has a more evident catalytic effect than a graphite anode. As shown in Figure 3, the variability of color reduction between electrolysis with and without a catalyst and using a Ti $\mid \mathrm{PbO}_{2}$ anode is greater than 20\%. Addition of titanium dioxide to this electrolysis substantially increases dye degradation.

As a semiconductor, titanium dioxide can be excited to give up or accept an electron. The holes with positive potential at the surface of titanium dioxide particles have large oxidizing ability.

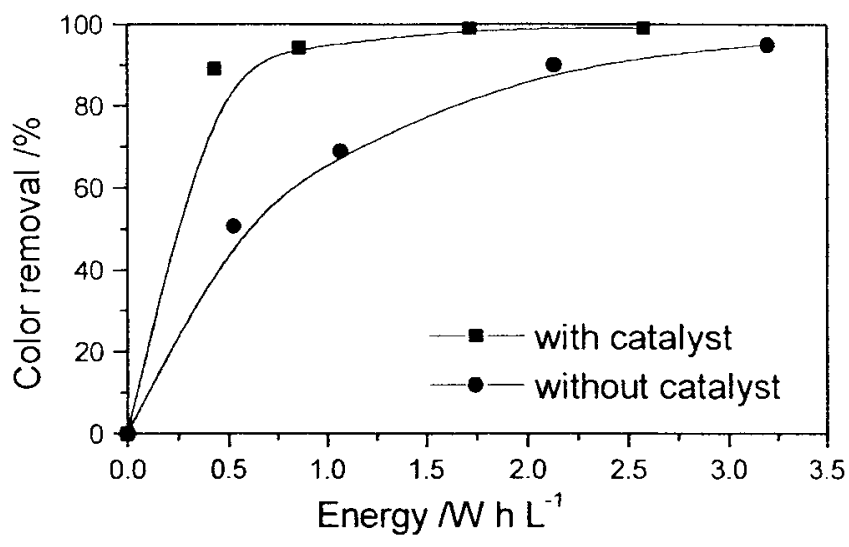

Figure 2-Color removal of dye Acid Red B (60 mg/L) using graphite anode at $8 \mathrm{~V}$ dc, with electric current density of $100 \mathrm{~mA} / \mathrm{cm}^{2}$ with a titanium dioxide catalyst and $124 \mathrm{~mA} / \mathrm{cm}^{2}$ without the catalyst. 


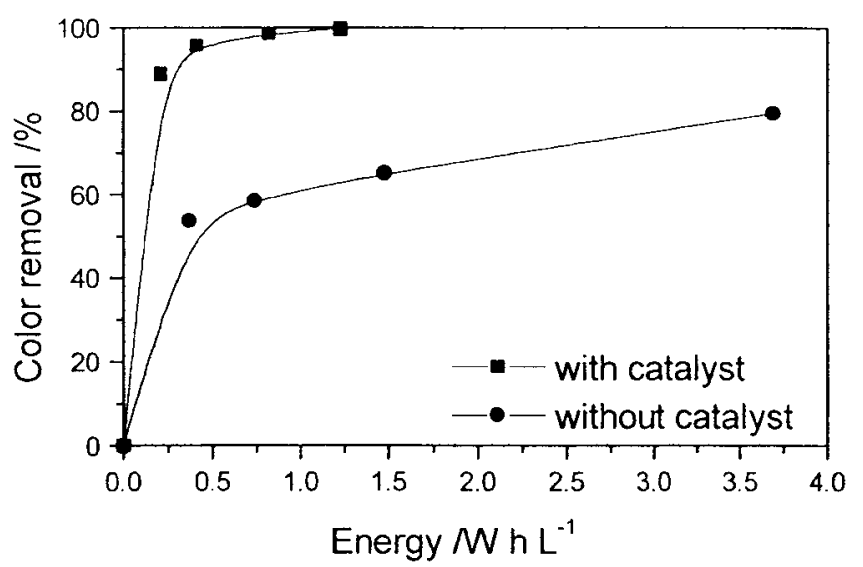

Figure 3-Color removal of dye Acid Red B (60 mg/L) using a $\mathrm{Ti} \mid \mathrm{PbO}_{2}$ anode at $8 \mathrm{~V}$ dc, with electric current density of $48 \mathrm{~mA} / \mathrm{cm}^{2}$ with a titanium dioxide catalyst and $52 \mathrm{~mA} / \mathrm{cm}^{2}$ without the catalyst.

Taghizadeh et al. (2000) considered having titanium dioxide preadsorb organic compounds at the particle-solution interface before degradation. Then, the titanium dioxide oxidizes the compounds directly or indirectly by direct oxidative transformation of the compounds that need to diffuse from the bulk solution to the semiconductor particle surface; and by oxidative radicals, such as ${ }^{\circ} \mathrm{OH}$ and ${ }^{\circ} \mathrm{O}_{2}$, generated from the oxidation of water or hydroxide ions by the valence bond holes at the surface of semiconductor particles. This preadsorption mechanism is responsible for the fast removal of dye at the beginning of the reaction. Because the semiconductor catalyst can be made more efficient by blending or loading with other elements, application of this catalytic system has great commercial potential.

Total Organic Carbon Removal. A similar conclusion can be drawn from the results in Figures 4 and 5 that titanium dioxide can improve the TOC removal ratio. However, these results indicate that the catalytic effect of the semiconductor using a graphite anode is not as great as that using a $\mathrm{Ti} \mid \mathrm{PbO}_{2}$ anode when other system conditions are equal. This observation is consistent with the

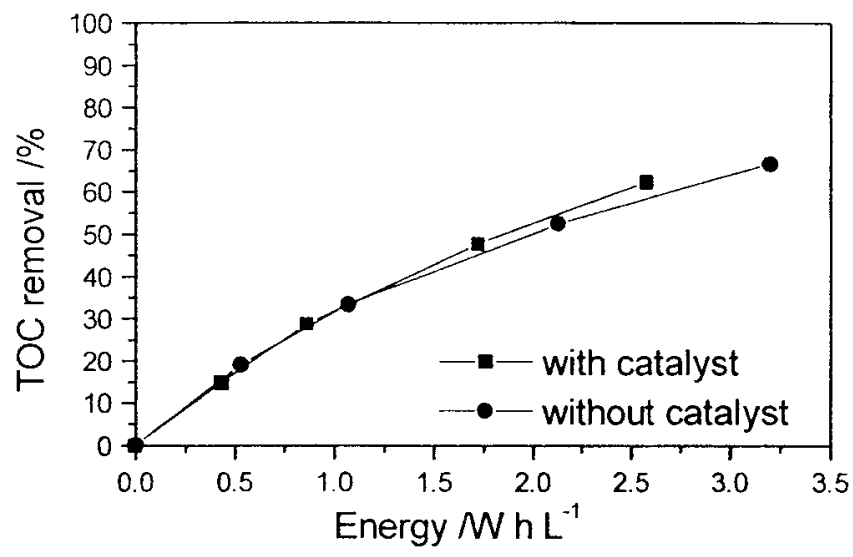

Figure 4-Total organic carbon removal of dye Acid Red B (60 mg/L) using a graphite anode at $8 \mathrm{~V} \mathrm{dc}$, with electric current density of $100 \mathrm{~mA} / \mathrm{cm}^{2}$ with a titanium dioxide catalyst and $124 \mathrm{~mA} / \mathrm{cm}^{2}$ without the catalyst.

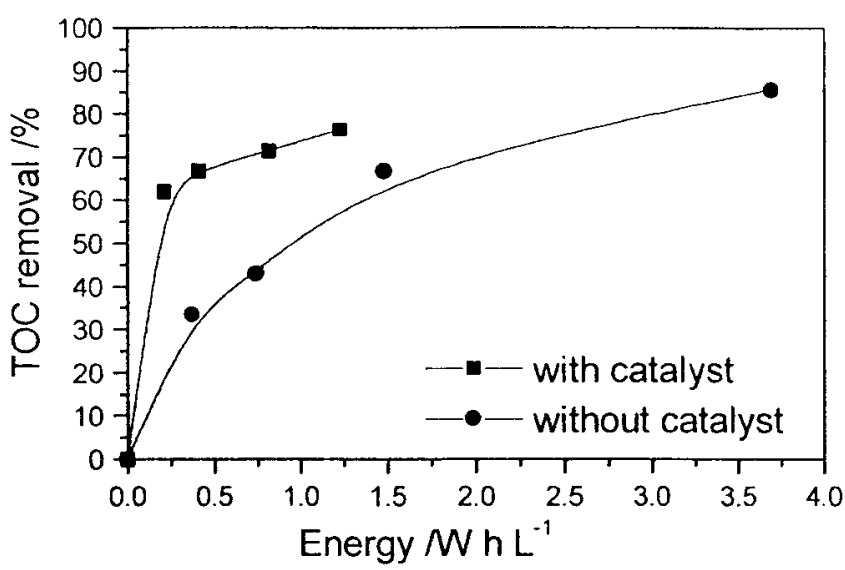

Figure 5-Total organic carbon removal of dye Acid Red $\mathrm{B}(60 \mathrm{mg} / \mathrm{L})$ using a Ti $\mid \mathrm{PbO}_{2}$ anode at $8 \mathrm{~V} \mathrm{dc}$, with electric current density of $48 \mathrm{~mA} / \mathrm{cm}^{2}$ with a titanium dioxide catalyst and $52 \mathrm{~mA} / \mathrm{cm}^{2}$ without the catalyst.

results for color removal. An explanation for this observation could be that the graphite anode may produce significant oxygen while the $\mathrm{Ti} \mid \mathrm{PbO}_{2}$ anode, a type of high-oxygen overvoltage anode, may transmit more electrons from titanium dioxide particles than from either water, hydroxide ions, or both. Consequently, it is rational to devise and apply many more efficient high-oxygen overvoltage anodes.

pH. A typical pH variation curve is tracked in Figure 6. Solution $\mathrm{pH}$ decreases gradually in the electrolysis process, starting at 6.5 and ending at approximately 3.8 to 4 . This shows that acidic compounds such as carbonic acid and carboxylic acid are produced during treatment. Solution $\mathrm{pH}$ changes similarly when a graphite anode is used.

Biodegradability. Biodegradability has been tested by comparing cultures of the solutions before and after treatment. After treatment, solutions were stored at normal temperature for a week. Bacterial colonies were found on the walls of the storage vessels. However, no bacteria were found in the solution of dye Acid Red $\mathrm{B}$ without degradation. Therefore, it can be concluded that biodegradability, which is also attributable to the breakdown of molecules, is enhanced after electrolysis.

Ultraviolet-Visible Spectrum. Typical UV-visible spectra of dye Acid Red B and treated dye solution are shown in Figures 7

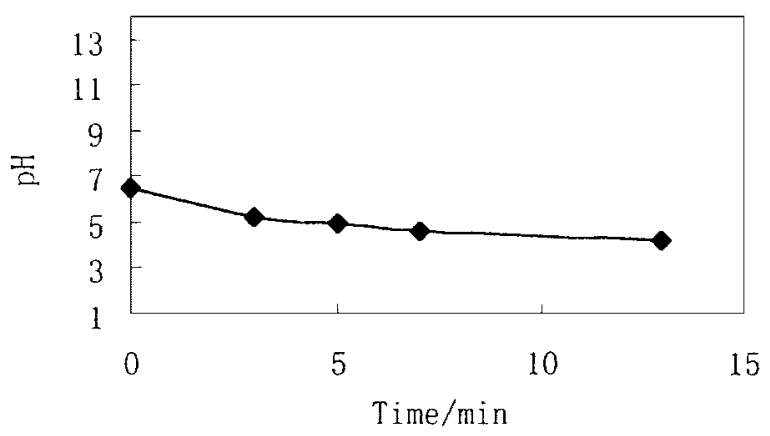

Figure 6-Typical pH variation in the catalytic electrolysis using a $\mathrm{Ti} \mid \mathrm{PbO}_{2}$ anode at $8 \mathrm{~V}$ dc, with an electric current density of $48 \mathrm{~mA} / \mathrm{cm}^{2}$. 


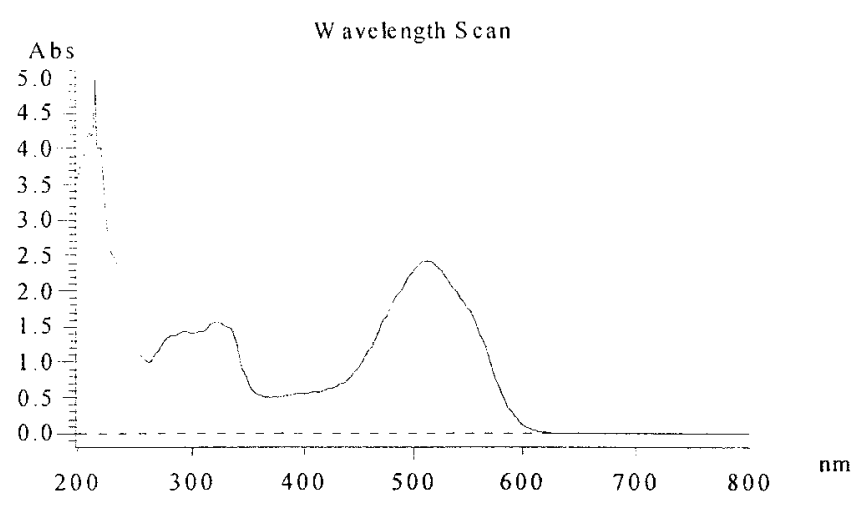

Figure 7-UV-visible spectrum of dye Acid Red B.

and 8 , respectively. There is a 514-nm maximum absorbency visible wavelength of dye Acid Red B. Additionally, there are absorbency peaks between 260 and $370 \mathrm{~nm}$. However, after treatment, these absorbency peaks disappear. At less than $250 \mathrm{~nm}$, the absorbency is still relatively high. Therefore, it can be concluded that during treatment the conjugated bonds of dye Acid Red B are destroyed and that the molecules are broken into smaller ones.

Electrochemical Measurements. The electrochemical behavior of the graphite anode is shown in Figure 9. There is an apparent dye oxidation peak from 0.65 to $0.85 \mathrm{~V}$ (versus the saturated calomel electrode $[\mathrm{SCE}])$ in dye solution $(10 \mathrm{~g} / \mathrm{L})$. This peak has not been observed in dilute solution $(60 \mathrm{mg} / \mathrm{L})$, which is similar to the result that Ronaldo et al. (1999) achieved in testing the behavior of the $\mathrm{Ti} / \mathrm{Ru}_{0.3} \mathrm{Ti}_{0.7} \mathrm{O}_{2}$ electrode in dye Reactive Blue 19 solution $(30 \mathrm{mg} / \mathrm{L})$. The oxidation current density can also be evaluated from the results. At $0.9 \mathrm{~V}$ (versus the SCE), the current density increases to approximately $3.5 \mathrm{~mA} / \mathrm{cm}^{2}$ in dye solution, while, in blank solution, the current density is approximately 2.5 $\mathrm{mA} / \mathrm{cm}^{2}$. The oxidation current density is calculated as $1.0 \mathrm{~mA} /$ $\mathrm{cm}^{2}$. Hence, it is logical that in dilute solution the oxidation current will not be large enough to be detected.

Infrared Spectrum. Figure 10 shows a typical IR spectrum of dye and organic compounds remaining in the solution after electrolysis at a color removal ratio of more than $95 \%$. The solution was added into surplus barium chloride, depositing the sulfate ion, then was condensed and air-dried to constant weight. Figure 10 shows that after electrolysis there are peaks at 2060, 1384, and 481 $\mathrm{cm}^{-1}$ coming forth, while peaks of 1052,1187 , and $1502 \mathrm{~cm}^{-1}$

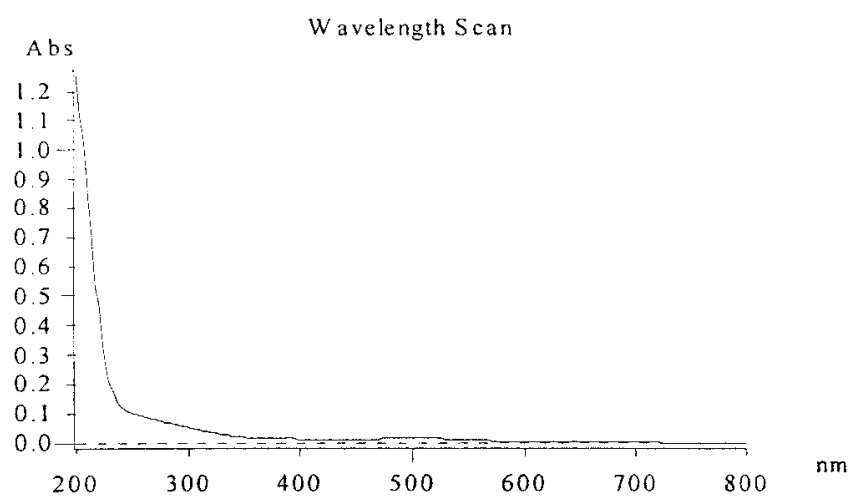

Figure 8-Typical UV-visible spectrum of dye solution after treatment.
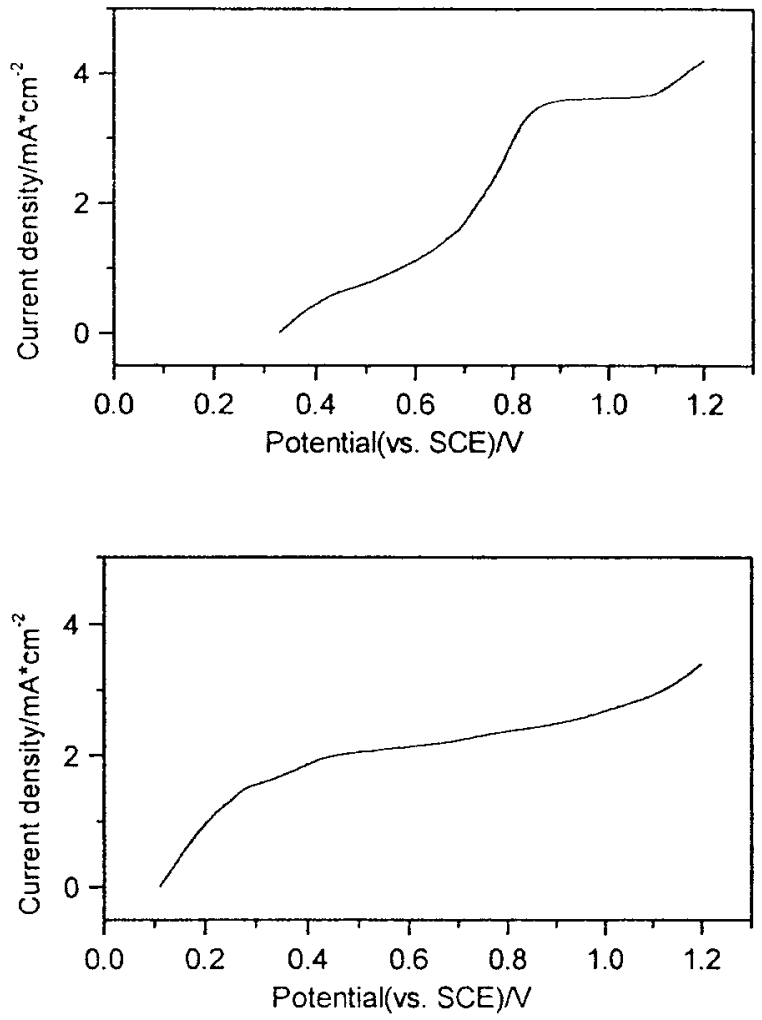

Figure 9-Current-potential behavior of a graphite anode ( $0.05 \mathrm{M}$ sodium sulfate) at $20 \mathrm{mV} / \mathrm{s}$ in (a) dye solution containing dye Acid Red B (10 g/L) and (b) blank solution without dye.

disappear. The peak at $2060 \mathrm{~cm}^{-1}$ is thought to belong to chloride and peaks at 1052 and $1187 \mathrm{~cm}^{-1}$ are thought to belong to alkyl sulfites, which precipitate on the addition of surplus barium chloride to the solution.

The peaks at 1384 and $481 \mathrm{~cm}^{-1}$ are considered as expressions of nitrites and the peak at $1502 \mathrm{~cm}^{-1}$ as an expression of the nitrogen-nitrogen double bond. Thus, it can be concluded that the nitrogen-nitrogen double bond must be attacked by the hydroxide or other radicals and then oxidized to nitrite.

\section{Conclusions}

This study confirms that addition of titanium dioxide to the electric field substantially increases the removal of color and TOC. A semiconductor catalyst can improve the electrolysis efficiency. This catalytic system provides a commercial alternative to treating dye wastewater. Additionally, the potential of the system will be greater if a more effective catalyst is found.

The investigation of mechanisms shows that acidic compounds, such as carbonic acid and $-\mathrm{COOH}$, are produced in the treatment. The conjugated bonds of dye Acid Red B must be destroyed and the molecules broken into smaller ones because the biodegradability of the solution increases and the UV-visible spectrum shows its maximum absorbency visible wavelength at $514 \mathrm{~nm}$; additionally, absorbency peaks at approximately 260 to $370 \mathrm{~nm}$ disappear after electrolysis. Results of the IR spectrum indicate that the nitrogennitrogen double bond of dye Acid Red B must be attacked by a hydroxide or other radical and then oxidized to nitrite. Finally, electrochemical measurements show an apparent dye oxidation 


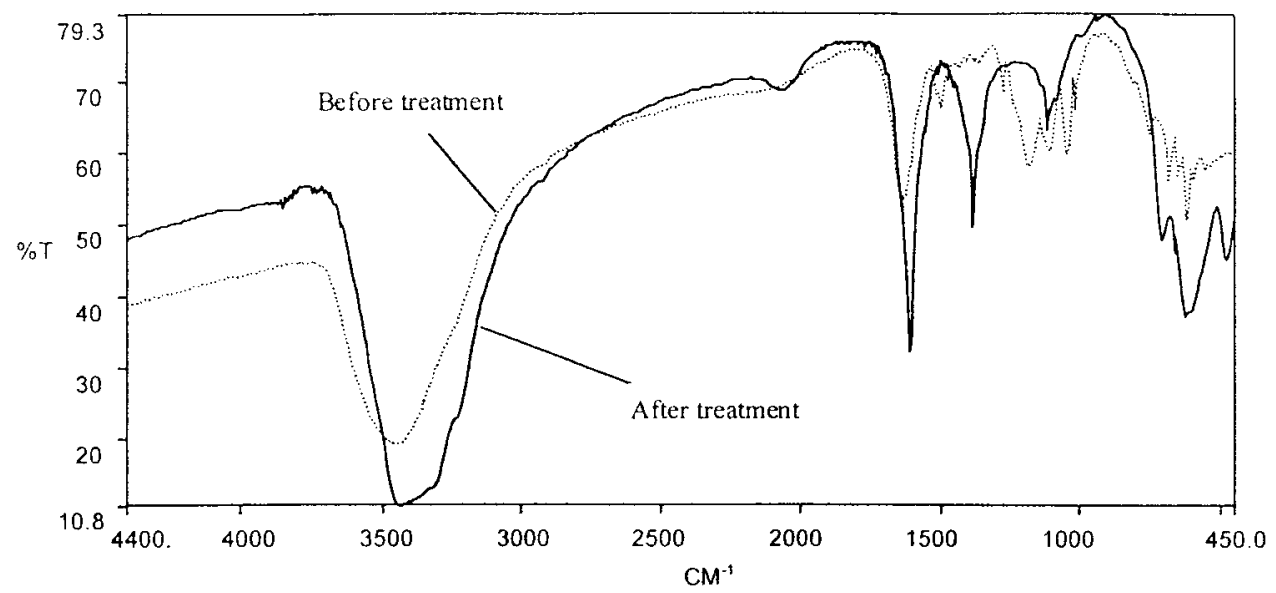

Figure 10-Typical IR spectrum of dye Acid Red B and organic compounds remaining in the solution after electrolysis at a color removal ratio of more than $95 \%$.

peak from 0.65 to $0.85 \mathrm{~V}$ (versus the SCE) in dye solution (10 $\mathrm{g} / \mathrm{L})$. This observation directly confirms that the oxidation mechanism takes effect in this catalytic system.

\section{Acknowledgments}

Credits. The authors acknowledge the financial support of the Chinese National Natural Science Foundation (29637010) for this study, Beijing, P.R. China.

Authors. W. Wang and J. Jia are professors at the School of Environmental Science and Engineering, Shanghai Jiaotong University, P.R. China, and X. Feng and W. Hu are graduates of the school. A. Peng is a professor at the State Key Laboratory of Environmental Aquatic Chemistry, Research Center for Ecoenvironment Sciences, Chinese Academy of Sciences, Beijing, and Z. Shen is a graduate of the program and school. Correspondence should be addressed to Z. Shen, State Key Laboratory of Environmental Aquatic Chemistry, Research Center for Eco-environment Sciences, Chinese Academy of Sciences, 18 Shuangqing Road, P.O. Box 2871, Beijing, 100085, P.R. China; e-mail: shenzhemin@sina.com.

Submitted for publication September 23, 2000; revised manuscript submitted October 25, 2001; accepted for publication November 19, 2001.

The deadline to submit Discussions of this paper is May 15, 2002.

\section{References}

Brillas, E.; Mur, E.; Sauleda, R.; Sanchez, L.; Peral, J.; Domenech, X.; and Casado, J. (1998) Aniline Mineralization by AOP's Anodic Oxidation, Photocatalysis, Electro-Fenton and Photoelectro-Fenton Processes. Appl. Catal., A, B16, 1, 31.

Campanella, L.; Crescentini, G.; and Militerno, S. (1995) Photobiodegradation of Chlorinated Water Pollutants by a Combined $\mathrm{TiO}_{2}-$ Polyaniline-Enzyme Catalytic System. Environmental Monitoring and Hazardous Waste Site Remediation, Proc. SPIE-Int. Soc. Optical Eng., Bellingham, Wash., T. Vo-Dinh (Ed.), 2504, 577.

Casado, J., and Brillas, E. (1996) Electrochemical Mineralization of Aniline: The Peroxi-Coagullation and Electro-Fenton Process. Proc. 10th Int. Forum Electrolysis Chem. Ind., Electrosynthesis, Lancaster, N.Y., 192.

Chen, W., and Zhu, X. (1998) Application to Organic Pollutants Treatment in Wastewater with $\mathrm{H}_{2} \mathrm{O}_{2}$ and $\mathrm{OH}$ Radical Generated by Electro Catalysis System. Zhongguo Huanjing Kexиe, 18, 2, 148.
DeFazio, S., and Lemley, A.T. (1999) Electrochemical Treatment of Acid Dye Systems: Sodium Meta-Bisulfite Addition to the Andco System. J. Environ. Sci. Health, Part A: Toxic/Hazard. Subst. Environ. Eng., 34, 2, 217.

Kesselman, J.M.; Lewis, N.S.; and Hoffman, M.R. (1997) Photoelectrochemical Degradation of 4 Chlorophenol at TiO2 Electrodes: Comparison Between Sorption and Photoreactivity. Environ. Sci. Technol., 31, 2298.

Lin, S., and Peng, C. (1996) Continuous Treatment of Textile Wastewater by Combined Coagulation Electrochemical Oxidation and Activated Sludge. Water Res., 30, 587.

Moctezuma, E.; Leyva, E.; Monreal, E.; Villegas, N.; and Infante, D. (1999) Photocatalytic Degradation of the Herbicide "Paraquat". Chemosphere, 39, 3, 511.

Naohide, T.; Yukio, M.; Masataka, Y.; Shin-ichi, W.; Sahori, T.; Zyun, S.; Kunishige, H.; and Hiroyasu, T. (1998) Application of Solid Polymer Electrolyte for Treatment of Water Colored by Dyestuffs. Treatment of Orange II. Mizu Kankyo Gakkaishi, 21, 1, 47.

Nicola, M., and Badea, T. (1996) Wastewater Treatment Using Electrochemical Oxidation of Organic Pollutants. Sci. Technol. Environ. Prot., 3, 1, 35.

Polcaro, A.M.; Palmas, S.; Renoldi, F.; and Mascia, M. (1999) On the Performance of $\mathrm{Ti} / \mathrm{SnO}_{2}$ and $\mathrm{Ti} / \mathrm{PbO}_{2}$ Anodes in Electrochemical Degradation of 2-Chlorophenol for Wastewater Treatment. J. Appl. Electrochem., 29, 2, 147.

Rodgers, J.; Jedral, W.; and Bunce, N. (1999) Electrochemical Oxidation of Chlorinated Phenols. Environ. Sci. Technol., 33, 9, 1453.

Ronaldo, P.; Patricio, P.; Adalgisa, de A.; Juan, R.; and Nelson, D. (1999) Electrochemically Assisted Photocatalytic Degradation of Reactive Dyes. Appl. Catal., B, 22, 2, 83.

Taghizadeh, A.; Lawrence, M.F.; Miller, L.; Anderson, M.A.; and Serpone, N. (2000) (Photo)electrochemical Behavior of Selected Organic Compounds on $\mathrm{TiO}_{2}$ Electrodes. Overall Relevance to Heterogeneous Photocatalysis, J. Photochem. Photobiol., A, A130, 2/3, 145.

Tezuka, M., and Jwasaki, M. (1996) Oxidative Degradation of Organic Pollutants in Water by Glow Discharge Electrolysis. Proc. Jpn. Soc. Promotion Sci. 3rd Asia-Pac. Conf. Plasma Sci. Technol., Tokyo, Jpn., 423.

Vlyssides, A.G., and Israilides, C.J. (1998) Electrochemical Oxidation of a Textile Dye and Finishing Wastewater Using a Pt/Ti Electrode. $J$. Environ. Sci. Health, Part A: Toxic/Hazard. Subst. Environ. Eng., A33, 5, 847.

Vlyssides, A.G.; Loizidou, M., Karlis, P.K., Zorpas, A.A.; and Papaioannou, D. (1999) Electrochemical Oxidation of a Textile Dye Wastewater Using a Pt/Ti Electrode. J. Hazard. Mater., B70, 41. 